\title{
Pretreatment determination of TPMT - state of the art in clinical practice
}

\author{
A. Teml • E. Schaeffeler $・$ M. Schwab
}

Received: 28 December 2008 / Accepted: 12 January 2009/Published online: 7 February 2009

(C) Springer-Verlag 2009

In this issue of the European Journal of Clinical Pharmacology, the impact of thiopurine S-methyltransferase (TPMT) polymorphisms on thiopurine use in clinical practice is presented.

Xin et al. investigated the relationship between TPMT phenotype and genotype $(T P M T * 2, * 3 A, * 3 B$, and $* 3 C$ ) and adverse drug reactions (ADR) in 150 Chinese kidney transplant patients under azathioprine treatment [1]. Twentyfour patients showed intermediate TPMT activity, and 126 had a normal or high activity. TPMT deficiency was not observed. Genetically, seven patients were heterozygous carriers for the $T P M T^{*} 3 C$ allele (allele frequency of $2.3 \%$ ), the most frequent allele in Asians. Other TPMT variants $(T P M T * 2, * 3 A, * 3 B)$ were not detected. Twelve patients experienced hematological ADR and another 18 patients experienced hepatological ADR followed by azathioprine treatment cessation or dose reductions. Generally, patients with hematological ADR, but not those with hepatological ADR, had a significantly lower TPMT activity than patients without ADR $(P<0.05)$. Four of the seven patients with heterozygosity developed ADR, two of them hematological and another two with hepatic

\footnotetext{
A. Teml

University Clinic of Psychiatry I, University of Ulm,

Ravensburg, Germany

E. Schaeffeler $\cdot$ M. Schwab $(\bowtie)$

Dr. Margarete Fischer-Bosch-Institute of Clinical Pharmacology, Stuttgart, and University of Tuebingen,

Tuebingen, Germany

e-mail: matthias.schwab@ikp-stuttgart.de

M. Schwab

Department of Clinical Pharmacology, University of Tuebingen, Tuebingen, Germany
}

side effects. The authors concluded that patients with a heterozygous genotype are at risk for developing hematotoxicity under treatment with azathioprine using standard dosage.

Efrati et al. determined the TPMT allelic variants TPMT*2, *3A, *3B, and $* 3 C$ in 881 unrelated healthy Israeli volunteers of Jewish $(n=531)$, Moslem $(n=194)$ or Druze $(n=156)$ descent [2]. The frequency of TPMT variants differed significantly among the three populations, with the highest frequency of heterozygous/homozygous variants in subjects of Druze origin (7.1\%), and the lowest frequency in those of Jewish origin (1.5\%). In Jews, only $T P M T^{*} 3 A$ was found (allele frequency $0.73 \%$ ), whereas in Druze TPMT*3A $(3.19 \%)$ and $T P M T^{*} 3 C(0.75 \%)$, and in Moslems TPMT*3C (1.05\%) and TPMT*3A $(0.79 \%)$ were determined. TPMT*2 and $* 3 B$ alleles were not detected. The authors concluded that the Israeli population is composed of three major diverse subpopulations, which may be important for genetic testing.

TPMT serves as a model for pharmacogenetic research. Large inherited variations in TMPT activity with a trimodal frequency distribution were described as early as 1980 by Weinshilboum et al. [3]. In a large population of more than 1,200 Caucasians, very low TPMT activity was determined in $0.6 \%$, and about 10 and $90 \%$ were found to be intermediate and normal/high methylators, respectively [4]. The most common variant alleles showing decreased activity are $T P M T^{*} 3 A(4.5 \%)$ and $T P M T^{*} 3 C(0.4 \%)$; all other mutations are rare $\left(T P M T^{*} 20.17 \%\right)$ or have been found only in single cases $[4,5]$.

In other ethnic groups, the frequency distribution differs significantly from that in Caucasians as summarized recently [6]. For instance, in subjects with African or Asian ancestry, $T P M T^{*} 3 C$ is the predominant allele with frequencies of $5.4-7.6 \%$ and $0.3-3 \%$, respectively $[6,7]$. Most 
recently, Schaeffeler et al. investigated 24 functionally relevant TPMT alleles in 586 Germans, 116 Ghanians, and 118 Koreans by MALDI-TOF mass spectrometry [8]. As expected, in the Ghanian and Korean populations, TPMT*3C was the most frequent variant allele. However, eight Ghanians were found to be heterozygous carriers for $T P M T * 8$ (allele frequency $3.4 \%$ ), and three Koreans showed heterozygosity for TPMT*6 (allele frequency $1.3 \%$ ). Both alleles appeared to be absent in Caucasians of German origin. This study demonstrates that a genotyping strategy can be recommended to replace measurement of TPMT activity only if either a complete genetic analysis of all currently known functionally relevant TPMT alleles is conducted or if the selection of all frequently known alleles in a certain ethnic population is performed.

Based on this information, it is of interest that the phenotype-genotype correlation in the work by Xin et al. is rather poor. Twenty-four patients with renal transplantation had an intermediate TPMT activity, but only seven patients had a heterozygous genotype. Thus, 17 patients with intermediate activity had a TPMT wild-type. The authors explained this discrepancy by concomitant drug treatment, red blood cell age, or blood transfusion, but as another important explanation, heterozygous carriers for TPMT* 6 could not be excluded. The same holds true for the paper by Efrati et al. [2]. Definite conclusions on the frequency distribution of TPMT activity or TPMT genotype cannot be drawn for populations of Middle Eastern origin until comprehensive phenotype-genotype correlations are studied.

A clinically important question is how predictive testing for TPMT may be to avoid dose-related ADR under treatment with thiopurines. In the present paper by Xin et al., a combination of azathioprine, prednisone, and cyclosporine A was used for immunosuppression of patients after renal transplantation [1]. Nine of the twelve patients with leucopenia, thrombopenia, or anemia showed intermediate TPMT activity, i.e., $75 \%$ of the hematologic ADR could be explained by TPMT. Severe myelotoxicity did not occur, which fits well with the absence of TPMT deficiency in the study population by Xin et al.

Patients with TPMT deficiency treated with standard doses of thiopurines are at approximately $100 \%$ at risk of developing severe and sometimes even fatal myelosuppression [9-12]. Because azathioprine and 6-mercaptopurine are metabolized by TPMT in hematopoetic cells, patients with TPMT deficiency accumulate excessive concentrations of the active compounds of azathioprine and 6-mercaptopurine. Pretreatment determination and pharmacogenetically guided thiopurine therapy have therefore been suggested for different diseases such as acute lymphoblastic leukemia (ALL) [13] and inflammatory bowel diseases (IBD) $[14,15]$ and should be performed routinely. An initial dose reduction to $10-15 \%$ of the standard thiopurine dose is a reliable approach for treatment of TPMT-deficient patients $[16,17]$. Nevertheless, it is important to note that leucopenia or myelosuppression can also be caused by other factors such as viral infections or drug-drug interactions (e.g., allopurinol) [18].

Hepatotoxicity was not associated with decreased TPMT activity in the manuscript by Xin et al. [1]. The mean prevalence of thiopurine-induced liver injury was 3.4\% in a recently published review [19]. Dubinsky et al. postulated for the first time that methylation capacity via TPMT leading to preferential 6-methyl-mercaptopurine (6-MMP) levels is associated with hepatotoxicity [20]. Children and adolescents with IBD and 6-MMP levels above $5,700 \mathrm{pmol} /$ $8 \times 10^{8}$ RBC had a threefold increased risk of hepatotoxicity compared to those with lower levels. Later, in a doseescalation approach in 6-MP nonresponders, the same investigators showed that higher doses of 6-MP led to preferential production of 6-MMP in a subset of patients, resulting in hepatotoxicity without initiating a therapeutic response [21]. The relationship was confirmed in children with ALL who were treated with 6-MP, revealing a significant correlation between elevated 6-MMP concentrations and aminotransferase levels [22]. Accordingly, Gardiner et al. recently presented three patients in whom thiopurine dose escalation based on clinical status and low to normal 6-thioguanine nucleotide levels resulted in severe hepatotoxicity, including liver failure in two cases, associated with very high 6-MMP levels of 26,000-40,000 pmol/ $8 \times 10^{8}$ RBC [23].

In conclusion, pretreatment TPMT determination is reasonable in clinical routine before commencing thiopurine therapy with subsequent pharmacogenetically guided dosing and is recommended to avoid hematotoxicity in patients treated with thiopurines. Genotyping is an attractive and highly sensitive and specific alternative to replace measurement of TPMT activity. Because the prevalence of TPMT alleles is ethnically different and ethnic heterogeneity is increasing, particularly in industrial countries, systematic genetic analysis of all currently known functionally relevant TPMT alleles is necessary. Since nongenetic aspects clearly predispose patients to ADR independent of TPMT, repeated laboratory controls have to be performed during thiopurine therapy.

Acknowledgement ES and MS were supported by the Robert Bosch Foundation, Stuttgart.

\section{References}

1. Xin HW, Xiong H, Wu XC, Li Q, Xiong L, Yu AR (2009) Relationships between thiopurine S-methyltransferase polymorphism and azathioprine-related adverse drug reactions in Chinese renal transplant recipients. Eur J Clin Pharmacol (in press) 
2. Efrati E, Adler L, Krivoy N, Sprecher E (2009) Distribution of TPMT risk alleles for thioupurine toxicity in the Israeli population. Eur J Clin Pharmacol (in press)

3. Weinshilboum RM, Sladek SL (1980) Mercaptopurine pharmacogenetics: monogenic inheritance of erythrocyte thiopurine methyltransferase activity. Am J Hum Genet 32:651-662

4. Schaeffeler E, Fischer C, Brockmeier D, Wernet D, Moerike K, Eichelbaum M, Zanger UM, Schwab M (2004) Comprehensive analysis of thiopurine S-methyltransferase phenotype-genotype correlation in a large population of German-Caucasians and identification of novel TPMT variants. Pharmacogenetics 14: 407-417

5. Samochatova EV, Chupova NV, Rudneva A, Makarova O, Nasedkina TV, Fedorova OE, Glotov AS, Kozhekbaeva Zh, Maiorova OA, Roumyantsev AG, Krynetski EY, Krynetskaia NF, Evans WE, Ribeiro RC (2009) TPMT genetic variations in populations of the Russian Federation. Pediatr Blood Cancer 52:203-208

6. van Dieren JM, van Vuuren AJ, Kuipers EJ, Hansen BE, Nieuwenhuis EE, van der Woude CJ (2006) Do ITPA and TPMT genotypes predict the development of side effects to AZA? Author reply. Gut 55:1048-1049

7. McLeod HL, Krynetski EY, Relling MV, Evans WE (2000) Genetic polymorphism of thiopurine methyltransferase and its clinical relevance for childhood acute lymphoblastic leukemia. Leukemia 14:567-572

8. Schaeffeler E, Zanger UM, Eichelbaum M, Asante-Poku S, Shin JG, Schwab M (2008) Highly multiplexed genotyping of thiopurine S-methyltransferase variants using MALD-TOF mass spectrometry: reliable genotyping in different ethnic groups. Clin Chem 54:1637-1647

9. Schwab M, Schaeffeler E, Marx C, Zanger U, Aulitzky W, Eichelbaum M (2001) Shortcoming in the diagnosis of TPMT deficiency in a patient with Crohn's disease using phenotyping only. Gastroenterology 121:498-499

10. Evans WE, Hon YY, Bomgaars L, Coutre S, Holdsworth M, Janco R, Kalwinsky D, Keller F, Khatib Z, Margolin J, Murray J, Quinn J, Ravindranath Y, Ritchey K, Roberts W, Rogers ZR, Schiff D, Steuber C, Tucci F, Kornegay N, Krynetski EY, Relling MV (2001) Preponderance of thiopurine S-methyltransferase deficiency and heterozygosity among patients intolerant to mercaptopurine or azathioprine. J Clin Oncol 19:2293-2301

11. Schwab M, Schäffeler E, Marx C, Fischer C, Lang T, Behrens C, Gregor M, Eichelbaum M, Zanger UM, Kaskas BA (2002) Azathioprine therapy and adverse drug reactions in patients with inflammatory bowel disease: impact of thiopurine S-methyltransferase polymorphism. Pharmacogenetics 12:429-436

12. Slanar O, Chalupná P, Novotný A, Bortlík M, Krska Z, Lukás M (2008) Fatal myelotoxicity after azathioprine treatment. Nucleosides Nucleotides Nucleic Acids 27:661-665

13. Cheok MH, Lugthart S, Evans WE (2006) Pharmacogenomics of acute leukemia. Annu Rev Pharmacol Toxicol 46:317-353

14. Sandborn WJ (2001) Rational dosing of azathioprine and 6mercaptopurine. Gut 48:591-592

15. Lichtenstein GR, Abreu MT, Cohen R, Tremaine W, American Gastroenterological Association (2006) American Gastroenterological Association Institute technical review on corticosteroids, immunomodulators, and infliximab in inflammatory bowel disease. Gastroenterology 130:940-987

16. Teml A, Schaeffeler E, Herrlinger KR, Klotz U, Schwab M (2007) Thiopurine treatment in inflammatory bowel disease: clinical pharmacology and implication of pharmacogenetically guided dosing. Clin Pharmacokinet 46:187-208

17. Kaskas BA, Louis E, Hindorf U, Schaeffeler E, Deflandre J, Graepler F, Schmiegelow K, Gregor M, Zanger UM, Eichelbaum M, Schwab M (2003) Safe treatment of thiopurine S-methyltransferase deficient Crohn's disease patients with azathioprine. Gut 52:140-142

18. Colombel JF, Ferrari N, Debuysere H, Marteau P, Gendre JP, Bonaz B, Soulé JC, Modigliani R, Touze Y, Catala P, Libersa C, Broly F (2000) Genotypic analysis of thiopurine S-methyltransferase in patients with Crohn's disease and severe myelosuppression during azathioprine therapy. Gastroenterology 118:1025-1030

19. Gisbert JP, González-Lama Y, Maté J (2007) Thiopurine-induced liver injury in patients with inflammatory bowel disease: a systematic review. Am J Gastroenterol 102:1518-1527

20. Dubinsky MC, Lamothe S, Yang HY, Targan SR, Sinnett D, Théorêt Y, Seidman EG (2000) Pharmacogenomics and metabolite measurement for 6-mercaptopurine therapy in inflammatory bowel disease. Gastroenterology 118:705-713

21. Dubinsky MC, Yang H, Hassard PV, Seidman EG, Kam LY, Abreu MT, Targan SR, Vasiliauskas EA (2002) 6-MP metabolite profiles provide a biochemical explanation for 6-MP resistance in patients with inflammatory bowel disease. Gastroenterology 122:904-915

22. Nygaard U, Toft N, Schmiegelow K (2004) Methylated metabolites of 6-mercaptopurine are associated with hepatotoxicity. Clin Pharmacol Ther 75:274-281

23. Gardiner SJ, Gearry RB, Burt MJ, Ding SL, Barclay ML (2008) Severe hepatotoxicity with high 6-methylmercaptopurine nucleotide concentrations after thiopurine dose escalation due to low 6thioguanine nucleotides. Eur J Gastroenterol Hepatol 20:1238-1242 